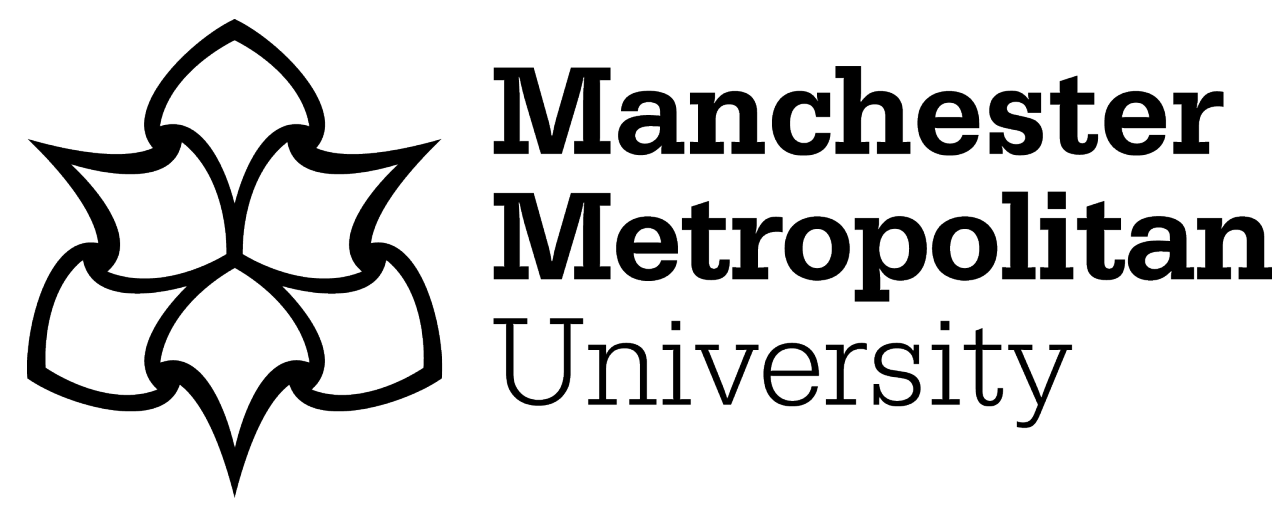

Halliwell, Jamie ORCID logoORCID: https://orcid.org/0000-0001-9088-9226 (2020) Applying Social Media Research Methods in Geography Teaching: Benefits and Emerging Challenges? Journal of Geography, 119 (3). pp. 108113. ISSN 0022-1341

Downloaded from: https://e-space.mmu.ac.uk/626058/

Version: Accepted Version

Publisher: Informa UK Limited

DOI: https://doi.org/10.1080/00221341.2020.1755717

Please cite the published version 


\title{
Applying Social Media Research Methods in Geography Teaching: Benefits and Emerging Challenges?
}

\author{
Jamie Halliwell (iD \\ School of Natural Sciences, Manchester Metropolitan University, Manchester, UK
}

\begin{abstract}
Students embody themselves within social media platforms and (re)craft their identities within social media platforms. These interfaces enable students to think critically regarding human geographic issues online and raise awareness of their positionalities in using ever-changing technology. This paper analy-ses how social media research can be developed into pedagogy, in relation to research that uses WhatsApp and Twitter as research methods to explore issues around identity within Eurovision Song Contest fandom. It argues that higher education institutions need to be continuously aware of the increasing need for digital integration into undergraduate geography teaching, fieldwork and pedagogy.
\end{abstract}

\section{Introduction: Digital transformations}

Academics and researchers are encouraged to engage with new creative ways to engage students within undergraduate teaching. Digital methods are one such way to connect with students, which can include using virtual learning environments, conducting 'Kahoot' quizzes; and also facilitating 'mobile learning' techniques that use tablet devices to stimulate collaborative learning in unprecedented ways (Ally 2009; Melhuish and Falloon 2010). Social media ${ }^{1}$ platforms, such as Instagram and Twitter can also be deployed as mobile methods in the classroom. These applications can encourage students to think critically about the deeper held meanings of the digital in our daily lives and the spatiality of information and communication. This can shape their self-awareness and self-reflexivity of how they use technology in their social interactions within their socio-cultural lives.

For academics, we are increasingly reliant upon using the internet and social media to disseminate our findings to a range of audiences, as well as to network with others. For geographers engaging within the digital realm, there is a need to examine its power within everyday socio-spatial relations (Ash, Kitchin, and Leszczynski 2018). This includes understanding the mechanical infrastructures that influence socio-spatial and economic processes, but also their contribution to human connectivity (Rose 2016). Digital embodiment is increasingly common through the influence of the internet and social media. As Haraway (2006) famously noted, cyborgs (and digital interfaces) have encouraged us to think about how our bodies go 'beyond the skin'. Haraway's 'cyborg politics' suggests how the digital influences subversion of the structures of language, desire, identity and social relations and how they can be recrafted by humans within digital platforms (Maliepaard 2015; Rose 2016; Jenzen 2017; Truong 2018a, 2018b).

Given these approaches toward digital geographic thinking, we also need to be informing students of the importance of the digital in daily life. Access to smartphone technologies and social media usage amongst young people is ubiquitous and are popular methods for communication and sharing information. Where students are increasingly digital savvy and become intrinsically reliant on digital communication to practice student identities (Holton 2019; Holton and Harmer 2019), digital methods are increasingly permeating their research projects. Academics have examined how students deploy social technologies to facilitate communication during fieldwork between group members and within public networks (Welsh et al. 2013; France et al. 2015). Where this research has been fruitful, social media offers more dynamic possibilities in shaping student research design. We are increasingly dependent on the digital in shaping our social, cultural, economic and political worlds; that also provide multiple media interpretations of these issues. I argue that academics and university ethics boards continually need to keep up-to-date regarding the potentials of using digital research methods within teaching and research as they are ever-evolving. Academics should also develop knowledge from students regarding how they use technology and social media to engage and practice their social and cultural lives. To do this, similar to other geographers (see Hall 2009; De Jong 2015; Wilkinson 2016), I use auto-ethnography to reflect firstly on the application of social media in my own research that used the social media applications WhatsApp and Twitter to explore issues around the geography of fan and sexual identity within Eurovision Song Contest (ESC) fandom. From identifying this digital 
research framework, I will then raise the issues and challenges with deploying these social media platforms with the undergraduate teaching context, as well the ethical implications I faced and how these challenges can hinder, or overcome, productive uses of social media in the undergraduate classroom and fieldwork.

\section{Applying social media in geography: Towards new qualitative horizons?}

Technology has become ever more omnipresent in unleashing new, alternative qualitative understandings of how we express and perform our identities through social media applications. Exploring how technology transforms our socio-spatial relations and economic and cultural activities is not new but is infinitely evolving. Academics have often been interested in how terrestrial life is mapped and located within social media programs. This has involved mapping, extracting and analyzing 'big data' sets, using quantitative approaches. This has also involved collecting social media data using specific GIS software; collecting geo-tagged social media data can assist in mapping urban functions (Stefanidis, Crooks, and Radzikowski 2013; Croitoru et al. 2015; Shelton 2017b). Academics have often deployed and reflected on the use of GIS software within the pedagogic context, for example through geocoding of data (van den Bemt et al. 2018) and adopting qualitative approaches within QualGIS research (Battista and Manaugh 2018). However, this has been criticized as providing simplistic arguments around space within human geography; situated analyses of geo-tagged data (for example by unpacking key words from Twitter tweets) is needed to construct more relational and multidimensional understandings of space within digital platforms (Shelton 2017b).

With the advent of smartphone and tablet technologies, individuals no longer simply consume information through digital screens, but are interactive participants in shaping the internet. These ubiquitous technologies encourage a 'scrolling' culture that is performed by haptic gestures. This is often the case with some locative smartphone dating applications, such as Tinder and Grindr that encourage users to find partners and intimacy in new hybrid, spatial and socio-technical ways (Miles 2018). There are other, more complex decisions that encourage people to perform such gestures, as images, text and representations across social media platforms trigger reactive emotional responses. This is also the case for many mainstream social media applications, such as Facebook (De Jong 2015), Instagram and Twitter, which encourage users to 'like' or 'favourite' a particular post or tweet. Social media is also a nexus that mobilizes groups of people to discuss many socio-cultural issues. For example, Butler, Schafran, and Carpenter (2018) examined imaginations of space and place on Twitter by collecting tweet data on urban spaces that referenced particular places as a '\#shithole'. Here they explored how residents living and not living in towns and cities engaged in territorial stigmatization. Similarly, Sandover, Kinsley, and Hinchliffe (2018) explored how animal activists on Twitter responded to calls from the UK government's legislation on badger culling in England and Zebracki and Luger (2019) have examined the role of memes as performative and political sites of public art within peer-to-peer social networking. These papers demonstrate how places and political activism can be performed through Twitter, where multiple identities can be expressed in unexpected ways. Research by Jenzen (2017) has examined how trans youth seek belonging through digital networks to authenticate their trans identities. Platforms such as Tumblr, YouTube and daily blogging practices provide them with the fluidity in defining themselves and forging like-minded networks. These examples demonstrate the importance of the internet and social media in producing new social relations and identity making. Drawing from my own doctoral research, in first and second-year undergraduate seminars and lectures, I have taught students about the performative role of social media and how cognitive processes, through haptic gestures, can materialize identity through multidimensional forms of communication (such as text, images, emojis). This also involved the sharing of WhatsApp group chat messages and Twitter tweets from my qualitative data collection to students, to raise their awareness of the importance of these social media applications in bringing identity into being and how ESC fans negotiate their fan, gender and sexual identities between social media and internet platforms. Demonstrating and adapting these examples within higher education pedagogy can be particularly useful to explore how the digital assists in creating imaginations of place, fuels political activism and resistance and encourage students to reflect on how they express themselves within online contexts. I will now turn to explore how digital research methods were deployed within my doctoral research, addressing the associated benefits and challenges, before exploring the possibilities of incorporating such methods into higher education geography teaching.

\section{Applying digital research methods in a research project: Exploring the gendered and sexual lives of Eurovision Song Contest (ESC) fans online}

Applying digital research methods within a teaching environment from a research project can demonstrate new innovative and experimental methods, but it can also be challenging. Here, I draw upon my doctoral research that used the social media applications WhatsApp and Twitter to examine issues around the expressions of gender and sexual identities amongst Eurovision Song Contest (ESC) fans through social media platforms and at ESC-related events. ESC fans are reliant on social media and the internet to practice their fandom daily, outside the annual nature of the event. These digital methods of communication encourage social networking with other fans and forging connections with others based on like-minded interests. Digital networks develop across multiple identity characteristics and specific contest cultural elements, such as music tastes, national cultures and languages. ESC fans themselves are located spatially and internationally, therefore applying digital research methods was appropriate to explore multiple international 
perspectives around issues of gender and sexuality within ESC fandom. First, the coordination of digital style focus groups called 'group chats' using the social media application WhatsApp were developed, requiring a manipulation of the traditional focus group data collection method. These were created to explore the daily experiences and practices of ESC fandom and how fans express their gender and sexuality within these contexts. Questions were prompted to participants regularly and who would also discuss the current ESC-related activities occurring at that time. Where this incorporates retrospection, similar to other traditional interviewing methods, it also allows participants to produce data 'on their own terms' (Leyshon, DiGiovanna, and Holcomb 2013:180). WhatsApp group chats provide scope to bypass economic and travel costs incurred with offline focus groups, which can be costly if groups meet on frequent occasions (Kneale 2001). Two group chats with a maximum of four participants in each took place parallel to each other during a one-week period, with a total of eight group chats taking place between February and March 2018.

Secondly, Twitter was implemented in this research to examine similar issues surrounding identity making and its performance online. I collected qualitative data and snowball sampled fan tweets between January and May 2018 and 2019 from fans from my own Twitter account. Data output from these focus groups can take multiple communicative forms, such as text-based messaging, images, voice messages, videos, GIFs ${ }^{2}$ and web links. WhatsApp thus allows fans to network using innovative audio, visual and textual vernacular (Crang 2015). Twitter is a highly engaging medium through which fans network with others and access to these software communication tools stimulates them to manipulate and rework their identities, providing multiple lenses through which gender and sexuality can be expressed (Cockayne and Richardson 2017). Both these social media platforms offer innovative ways of engaging students within undergraduate teaching, as their lives are increasingly coded in time and space and often organize their social and cultural worlds through social media (Schwanen and Kwan 2008; Truong 2018b, 2018a). Where WhatsApp and Twitter offer exciting opportunities in conducting qualitative research in geography, I will now turn to how they could be implemented in undergraduate teaching contexts, such as seminars and fieldwork and address their respective challenges and ethical issues.

\section{Teaching social media: Benefits and new challenges?}

Universities are often scrutinized for their quality of teaching through national student surveys and the Teaching Excellence and Student Outcomes Framework (UCAS 2017) and as academics we need to find culturally credible ways to engage with students 'on their own terms' (Leyshon, DiGiovanna, and Holcomb 2013:180). Making use of the internet and social media within undergraduate geography teaching provides a means of doing so; these are essential tools to help students understand how these spaces influence their social and cultural worlds and how they intersect with terrestrial life. Students and young people are increasingly digitally savvy and social media literate and capitalizing on this knowledge within geographic teaching can be appropriate to explore contemporary social and cultural issues. Technology has become embedded in daily student life and it is essential to encourage students to develop critical thinking around, for example, how smartphones contribute to the digital embodiment of identity, mobilities and placemaking (Holton 2019). Working with students in delivering social media research methods encourages reciprocal learning. Academics can gain insight into student knowledge around social media use and their access to information. This adds a new dynamic to blended approaches that incorporate elearning and face-to-face teaching; which can complement varying learning styles and mechanisms (Mitchell and Forer 2010). Using social media produces hybrid assemblages where 'real-life' can be replicated, but also creates new socio-spatial relations, for which blended learning can be complementary.

There are multiple ways lecturers can deliver teaching that uses social media to explore human geographical issues. Firstly, Twitter was used during a second-year undergraduate lecture for the 'Social and Cultural Geography' unit at Manchester Metropolitan University (MMU). It was used at the start of the lecture to explore how students express their identities on social media platforms, and to elicit analytical thinking surrounding the power of these applications in representing and performing multidimensional aspects of identity, such as gender, sexuality, age, hobbies and interests. Students were asked to post a tweet to describe their identities and use a hashtag (using the acronym of the unit and the number of the lecture), so that myself, as the lecturer, could find these tweets within the Twitter application. Where students did not use or have access or use Twitter, in order to maintain an inclusive classroom for students who do not have access to internet-enabled devices, I asked them to write down how they would describe their identities in a few words. Using Twitter does encourage students to think about how they describe themselves within the remit of 280 characters, as well as allowing for multiple communication forms, such as pictures, emojis and GIFs. At the beginning of the lecture, I identified myself as a doctoral researcher to the students, which may have disrupted lecturer/student power relations within the lecturer theater environment, and coupled with the embarrassment that students may feel in engaging with the lecture in front of their peers, may have generated minimal responses to the task. Deploying this task may be more appropriate to use within a seminar, or small working group environment. Moreover, not every student had access, or used Twitter for social media engagement, limiting opportunities for students to be involved with the digital element of the lecture (Shelton 2017a). Geographers have argued about the ethical issues surrounding students and/or lecturers peering over their shoulders when delivering digital research methods (Holton and Harmer 2019). Other ethical issues are also prevalent, such as posting information about identity within a different social media profile 
and whether students, but also lecturers, hold responsibility and accountability in sharing and storing student's personal information within the teaching context.

Further, during a 'digital research methods' first-year workshop for undergraduates at MMU, a widening participating and social and culturally diverse university (Manchester Metropolitan University 2020), myself and my colleague tasked students with exploring student identities around Manchester. Initially, we considered coordinating digital group chats through WhatsApp and allow students to conduct participant observation on MMU campus to explore issues around the spatiality of student identity and relay their findings via the social media application, using multiple communication techniques (such as sending videos, images and text). However, we were concerned whether students would use these group chats morally, which also involved their sharing of mobile phone numbers within their groups, which is required to use WhatsApp. There are also concerns regarding the digital safety of students when sharing such information publicly within these group chats, as they could be exposed to harassment and doxing, away from the view of lecturers (Willard 2011).

Consideration must be given regarding which social media platforms are appropriate to use with students and be thoroughly risk-assessed. Given that we want to teach students the benefits of digital social media methods and encourage such learning as reciprocal, its implementation still requires regulation; thus, reinforcing lecturer-student power relations. Particularly as issues around data ownership and its accessibility can cause potential ethical dilemmas (Holton and Harmer 2019), which would require to rework ethics forms to submit to university ethics boards. Therefore, careful and advanced planning is necessary to incorporate such digital research methods in undergraduate student workshops. University ethics boards need to adapt to incorporate these emerging digital research methods, both for teaching and research, by acknowledging digital ethical guidance criteria, such as those produced by the Association of Internet Researchers (AOIR) (Association of Internet Researchers 2019).

To mitigate this, we decided to maintain teaching within the seminar room and give students the task of exploring how student identities around Manchester are constructed and experienced across multiple social media platforms, such as Twitter, Facebook, Instagram and the messaging board Reddit. Students formed groups and using their smartphones, tablets and laptops to explore these issues, thus ensuring students had access to at least one device (Shelton 2017a). Students were then able to explore issues surrounding student identity and its embodiment within social media applications 'on their own terms' (Leyshon, DiGiovanna, and Holcomb 2013:180) and allowed to conduct research within their own 'natural' settings (Holton and Harmer 2019). Students then shared their findings in terms of screenshots and links to content they had found on these social media platforms with the researchers and the class. Students uploaded their content to Padlet, a free website, which operates as a visual picture board, collating and organizing images and documents. However, this required regulation and we stipulated that students should not share any inappropriate or explicit imagery that could be harmful to the class. Students presented their findings and encouraged discussion with the lecturers who then pinpointed codes for analysis to develop their critical thinking. Students can gain new insights into the social media applications they use frequently, challenging their perceptions regarding how they operate, and encouraging them to think more critically regarding media representations. This encouraged studentled learning; as lecturers, we were increasingly aware of our positionalities as we are able to observe and relate to how the students generate and understand student identity in our presence and online. This was achieved in real-time, but also retrospectively as students reflected on how their student identities were constructed, stereotyped and marketed through multiple social media sites. Where this can be beneficial, lecturers need to be kept abreast of new technological developments and their changes and they need to be aware of the technologies that students are using to organize their identities and social lives (Shelton 2017a), in order to deliver them effectively within the pedagogical context.

\section{Conclusions}

This paper has argued that students and lecturers can learn through reciprocity in understanding the role of social media applications in shaping daily life and how they produce alternative knowledges around digital embodiment, identity and placemaking. Moreover, I suggest that university ethics boards need to work with academics in order to deliver and implement sound ethics frameworks for geographers using digital research methods; both in undergraduate and postgraduate pedagogy and research. This could be achieved by referring to the ethics criteria produced by the AOIR by university ethics boards, but also through our own auto-ethnographies and reflections of deploying social media research methods in the classroom and in our own research projects. Practices such as diarizing or uploading our reflections to social media platforms could be useful to ourselves and others when we are increasingly scrutinized by students to deliver new and creative teaching methods (UCAS 2017); thus, digital tools are one way of achieving this.

Social media is highly appropriate to interact with students in the pedagogic context as it demonstrates lecturer awareness of the technology within students' everyday lives. Additionally, it encourages students to develop critical thinking of their own use of social media and smartphone technologies that are ever-evolving. Students can become more aware of their positionality online and their immersion with smartphones and social media can provide new critical ways of human geographic thinking. Lecturers can also witness and relate to how these positionalities and identities are being generated face-to-face and also online. From using my knowledge and use of social media platforms in my research and personal life, being aware of the changes and updates in technology is useful in order to use them within the teaching context. By encouraging students to learn on 'on their 
own terms', they can produce culturally credible information to share back to teachers and fellow students (Leyshon, DiGiovanna, and Holcomb 2013:180; Wilkinson 2016). This also can raise lecturer awareness of the technologies students use to connect with their social and cultural worlds, which can enhance future learning. Incorporating social media methods within teaching can breakdown the boundaries between student/lecturer relationships as lecturers can encourage student-led learning, but also stimulate reciprocal learning between lecturers and students (France et al. 2015).

Within undergraduate teaching, lecturers also need to be aware of their positionality when delivering teaching relating to social media methods. This can involve entrusting responsible use of these platforms to students and making decisions as to how such sessions should be regulated. Keeping students in the classroom and accessing digital portals through multiple screens to explore social and cultural issues is one form of regulation. However, if we are to allow students to use social media in such a way that involves group fieldwork and interaction with the terrestrial environment, then this poses new ethical and moral challenges regarding access and usage of social media data and group cohesiveness and behavior (Holton and Harmer 2019). Applying digital research methods within teaching can raise new challenges, but also provide benefits regarding the negotiation of our own researcher and lecturer positionalities. The consistent development and innovation of social media will continually open up new geographical possibilities and challenges both in research, teaching and ethics.

\section{Notes}

1. In this paper, I specifically refer to social media applications that stimulate networking between users, that can also produce different forms of language output, such as text, emojis, images, videos and GIFs.

2. GIF is an acronym for graphics interchange format. It refers to a short, animated digital object where a group of images are collected and played in a sequence, so they appear to move.

\section{Notes on contributor}

Jamie Halliwell is a $\mathrm{PhD}$ candidate at Manchester Metropolitan University, UK. His research examines the case study of the Eurovision Song Contest (ESC) and its fandom as a nexus for the shaping of gender and sexual identities within digital fan spaces.

\section{ORCID}

Jamie Halliwell (iD http://orcid.org/0000-0001-9088-9226

\section{References}

Ally, M. 2009. Mobile learning: Transforming the delivery of education and training. Vancouver: Marquis Book Printing.

Ash, J., R. Kitchin, and A. Leszczynski. 2018. Digital turn, digital geographies? Progress in Human Geography 42 (1):25-43. doi: 10.1177/ 0309132516664800.

Association of Internet Researchers. 2019. Ethics-AoIR. Accessed March 24, 2019. https://aoir.org/ethics/.
Battista, G. A., and K. Manaugh. 2018. Illuminating spaces in the classroom with qualitative GIS. Journal of Geography in Higher Education 42 (1):94-109. doi: 10.1080/03098265.2017.1339267.

Butler, A., A. Schafran, and G. Carpenter. 2018. What does it mean when people call a place a shithole? Understanding a discourse of denigration in the United Kingdom and the Republic of Ireland. Transactions of the Institute of British Geographers 43 (3):496-510. doi: 10.1111/tran.12247.

Cockayne, D. G., and L. Richardson. 2017. A queer theory of software studies: software theories, queer studies. Gender, Place \& Culture 24 (11):1587-94. doi: 10.1080/0966369X.2017.1383365.

Crang, M. 2015. The promises and perils of a digital geohumanities. Cultural Geographies 22 (2):351-60. doi: 10.1177/1474474015572303.

Croitoru, A., N. Wayant, A. Crooks, J. Radzikowski, and A. Stefanidis. 2015. Linking cyber and physical spaces through community detection and clustering in social media feeds. Computers, Environment and Urban Systems 53:47-64. doi: 10.1016/j.compenvurbsys.2014.11. 002 .

De Jong, A. 2015. Using Facebook as a space for storytelling in geographical research. Geographical Research 53 (2):211-23. doi: 10 1111/1745-5871.12095.

France, D., W. B. Whalley, A. Mauchline, V. Powell, K. Welsh, A. Lerczak, J. Park, and R. Bednarz. 2015. Social networking, communication and student partnerships. In Enhancing fieldwork learning using mobile technologies, eds. France, D., Whalley, W. B., Mauchline, A., Powell, V., Welsh, K., Lerczak, A., Park, J., and Bednarz, R. S., 85-99. Cham: Springer International Publishing (Springer Briefs in Ecology).

Hall, S. M. 2009. "Private life" and "work life": Difficulties and dilemmas when making and maintaining friendships with ethnographic participants. Area 41 (3):263-72. doi: 10.1111/j.1475-4762.2009. 00880.x.

Haraway, D. 2006. A cyborg manifesto: Science, technology, and socialist-feminism in the late 20th century. In The international handbook of virtual learning environments, eds. Weiss, J., Nolan, J., Hunsinger, J., and Trifonas, P., 117-58. Dordrecht: Springer Netherlands.

Holton, M. 2019. Walking with technology: understanding mobilitytechnology assemblages. Mobilities 14 (4):435-17. doi: 10.1080/ 17450101.2019.1580866.

Holton, M., and N. Harmer. 2019. "You don't want to peer over people's shoulders, it feels too rude!" The moral geographies of using participants' personal smartphones in research. Area 51 (1):134-41. doi: 10.1111/area.12425.

Jenzen, O. 2017. Trans youth and social media: moving between counterpublics and the wider web. Gender, Place \& Culture 24 (11): 1626-41. doi: 10.1080/0966369X.2017.1396204.

Kneale, J. 2001. Working with groups. In Qualitative methodologies for geographers: Issues and debates, eds. Limb, M. and Dwyer, C., 136-52. London: Arnold.

Leyshon, M., S. DiGiovanna, and B. Holcomb. 2013. Mobile technologies and youthful exploration: stimulus or inhibitor? Urban Studies 50 (3):587-605. doi: 10.1177/0042098012468897.

Maliepaard, E. M. 2015. Bisexuals in space and geography: more-thanqueer? Fennia-International Journal of Geography 193 (1):148-59. doi: $10.11143 / 46303$.

Manchester Metropolitan University. 2020. Equality and diversity. Manchester Metropolitan University. Accessed February 5, 2020. https://www2.mmu.ac.uk/about-us/equality-and-diversity/.

Melhuish, K., and G. Falloon. 2010. Looking to the future: M-learning with the iPad. Computers in New Zealand Schools 22 (3):1-16.

Miles, S. 2018. Still getting it on online: Thirty years of queer male spaces brokered through digital technologies. Geography Compass 12 (11):e12407. doi: 10.1111/gec3.12407.

Mitchell, P., and P. Forer. 2010. Blended learning: The perceptions of first-year geography students. Journal of Geography in Higher Education 34 (1):77-89. doi: 10.1080/03098260902982484.

Rose, G. 2016. Rethinking the geographies of cultural "objects" through digital technologies: Interface, network and friction. Progress in Human Geography 40 (3):334-51. doi: 10.1177/0309132515580493. 
Sandover, R., S. Kinsley, and S. Hinchliffe. 2018. A very public cullThe anatomy of an online issue public. Geoforum 97:106-18. doi: 10.1016/j.geoforum.2018.08.016.

Schwanen, T., and M.-P. Kwan. 2008. The Internet, mobile phone and space-time constraints. Geoforum 39 (3):1362-77. doi: 10.1016/j.geoforum.2007.11.005.

Shelton, C. 2017a. Giving up technology and social media: why university lecturers stop using technology in teaching. Technology, Pedagogy and Education 26 (3):303-21. doi: 10.1080/1475939X.2016. 1217269.

Shelton, T. 2017b. Spatialities of data: mapping social media "beyond the geotag". GeoJournal 82 (4):721-34. doi: 10.1007/s10708-0169713-3.

Stefanidis, A., A. Crooks, and J. Radzikowski. 2013. Harvesting ambient geospatial information from social media feeds. GeoJournal 78 (2): 319-38. doi: 10.1007/s10708-011-9438-2.

Truong, J. 2018a. Attending to others: how digital technologies direct young people's nightlife. Geographica Helvetica 73 (2):193-201. doi: 10.5194/gh-73-193-2018.

Truong, J. 2018b. Collapsing contexts: social networking technologies in young people's nightlife. Children's Geographies 16 (3):266-78. doi: 10.1080/14733285.2018.1458214.
UCAS. 2017. Teaching Excellence Framework (TEF)—what you need to know. UCAS. Accessed February 4, 2020. https://www.ucas.com/ undergraduate/what-and-where-study/choosing-course/teaching-excellence-framework-tef-what-you-need-know.

van den Bemt, V., J. Doornbos, L. Meijering, M. Plegt, and N. Theunissen. 2018. Teaching ethics when working with geocoded data: A novel experiential learning approach. Journal of Geography in Higher Education 42 (2):293-310. doi: 10.1080/03098265.2018. 1436534.

Welsh, K. E., A. L. Mauchline, J. R. Park, W. B. Whalley, and D. France. 2013. Enhancing fieldwork learning with technology: practitioner's perspectives. Journal of Geography in Higher Education 37 (3):399-415. doi: 10.1080/03098265.2013.792042.

Wilkinson, S. 2016. Hold the phone! Culturally credible research "with" young people. Children's Geographies 14 (2):232-8. doi: 10.1080/ 17597269.2015.1134761.

Willard, N. 2011. Cyber savvy: Embracing digital safety and civility. London: Sage.

Zebracki, M., and J. Luger. 2019. Digital geographies of public art: New global politics. Progress in Human Geography 43 (5):890-909. doi: 10.1177/0309132518791734. 